\title{
The Application of Ceramic Coatings in Petroleum Chemical and Building Industries
}

\author{
Wang Lan ${ }^{1,2}$, Feng Kexing ${ }^{1}$, Yang Liang ${ }^{1}$, Wang botao ${ }^{1}$ \\ 1. Tianjin Fire Research Institute, \\ 2. Tianjin University \\ Tianjin, China \\ e-mail: wanglan@tfri.com.cn
}

\begin{abstract}
Ceramic Coating was initially applied to aerospace field. Nowadays, it is widely applied to petrochemical industry and building fields. This paper introduces the classification, application status, research progress and extant question of Nanometer Ceramic Coating in order to offer some thoughts and reference for follow-up studies.
\end{abstract}

Keywords-ceramic coating; reflective thermal insulation; thermal conductivity

\section{INTRODUCTION}

Ceramic Coating was developed by several processes involving a variety compositions of polymer, ceramic powder filler, water and various additives. Nanometer Ceramic Coating was developed in recent years as the application of Nanometer technology, which combined special waterborne inorganic binder, introduced Ceramic beads reflection heat insulation heat preservation material with high reflectivity and high thermal resistance. Ceramic Coating was widely used, which was applied to surfaces of all kinds of material which need heat insulation.

\section{THE CHARACTERISTICS AND CLASSIFICATION OF CERAMIC COATING}

According to the three conduction mechanism of the heat, the building insulation ceramic coating can be divided into three categories: block building insulation ceramic coating, reflective thermal insulation coating, radiant insulation coating. The three kinds of coating of different mechanism of thermal insulation have their advantages and disadvantages.

Block building insulation ceramic coating is always made of ceramic powder fillers, additives and light weight, low coefficient of thermal conductivity of inorganic silicate filler. It achieves the effect mainly through blocking heat transfer way of heat. Block type thermal insulation coatings raw materials are accessible and low cost. The preparation technology and equipment is simple, construction is convenient. However, its heat preservation and heat insulation effect is relatively poor, easily form thermal bridge. The coating is thicker, the internal structure is loose, bibulous rate is high, easily fall off, and once the coating absorbed water, heat preservation and heat insulation coating effect would weaken obviously. In order to avoid coating absorbing water, protective layer is necessary.

Reflective thermal insulation coating can also be called solar heat reflection coating, developed from the basis of aluminum reflective coatings. Reflective thermal insulation coating is always made of sunlight high reflectivity and low absorption rate of pigments and fillers, binders and additives preparation. Reflective thermal insulation coating preparation technology is generally similar with ordinary architectural coatings. The kind of coating needs High adhesion rate of the base material, a strong waterproof dirt resistance and weather ability, but need additional protective layer when used for wall. This kind of coating can prevent heat from its source to the internal transfer object. However, most reflective thermal insulation coating is solvent coatings currently. How to develop the performance of waterborne reflection heat insulation coating will be work focus of scientific research workers and enterprise technical personnel in the future.

Radiant heat insulation coatings can also be called infrared radiation heat insulation building coatings. The radiation rate of Infrared ceramic powder such as functional filler under room temperature or high temperature is higher than general object. Radiant heat insulation coating making use of the properties, achieve the purpose of radiation thermal insulation through adding the right amount of infrared ceramic powder to the coating of high emissivity packing. Process of the raw materials of radiant heat insulation coatings process is relatively complex, high cost, performance is not stable enough. The mechanism of radiation heat insulation is not yet mature. Radiation heat insulation is currently still in the stage of research and actual application is less. Only applications in metallurgy and special jobs, such as used in the manufacture of protective clothing, protective clothing to reflect the high temperature object.

\section{The APPLICATION OF CERAMIC COATING}

\section{A. The Application in the Aerospace}

The ceramic material is first appeared on the American spacecraft. The heat-resistant tiles which are about $3 \mathrm{~cm}$ thick usually consists of two parts: high radiation ceramic materials which are less than $1 \mathrm{~mm}$ thick and coated on the outer, high temperature ceramic fiber with very low thermal conductivity coated internally. available from Russian and U.S. spacecraft thermal protection materials perspective, there are several thermal protection materials available in Russian and the U.S.: the first one kind is radiation heat- 
resistant material using refractory metal skin painted with high radiation coating; the second one kind is endothermic heat-resistant structural materials used early, absorbing through heat-resistant skin made by alloys with large heat capacity and high-temperature, then preventing heat transferring into the spaceship by the insulation material. The third one kind is ablative material, usually used for the reentry heat in the disposable spacecraft. It is mainly low thermal conductivity of composite materials composed of fiber materials or porous particles. The principle is to take a lot of heat and leave a porous carbon layer through thermochemical decomposition and gasification of organic matter playing the role of insulation, high temperature effects.

\section{B. Petrochemical Industry}

Ceramic insulation coatings have been widely used in the petrochemical industry, such as petroleum storage tanks, chemical pipelines, mobile tankers, liquefied gas cans.

1) External floating roof oil tank: External floating roof oil tank is mainly used for storage of crude oil or heavy oil. High pour point, high viscosity oil requires a high storage temperature, however, temperature could be up to about $60 / 70^{\circ} \mathrm{C}$ because the solar radiation on the tank roof surface is strong in the summer daytime. Most of the remaining time, temperature on the tank outside surface is lower than the storage temperature. So we need to set the tank insulation measures and heating facilities. Reflection and insulation ceramic coating can enhance the roof insulation: it can reduce heat loss and save energy in winter and block solar radiation, reduce oil evaporation loss in summer.

TABLE 1 THE HEAT DisSIPATION DESIGN AND ANALYSIS OF A $5000 \mathrm{~m}^{3}$ STEEL FLOATING ROOF TANK TOP

\begin{tabular}{|c|c|c|}
\hline The situation of the roof insulation & $\begin{array}{c}\text { No } \\
\text { insulation }\end{array}$ & insulation \\
\hline The temperature of the medium in the tank $/{ }^{\circ} \mathrm{C}$ & 65 & 65 \\
\hline Average atmospheric temperature $/{ }^{\circ} \mathrm{C}$ & 10 & 10 \\
\hline $\begin{array}{c}\text { Thermal conductivity of insulation } \\
\text { materials } /\left(\mathrm{W} /\left(\mathrm{m}^{2} .{ }^{\circ} \mathrm{C}\right)\right)\end{array}$ & - & 0.058 \\
\hline $\begin{array}{c}\text { Single plate heat transfer coefficient } /\left(\mathrm{W} /\left(\mathrm{m}^{2} .{ }^{\circ} \mathrm{C}\right)\right) \\
\text { overall heat transfer coefficient of the } \\
\text { Tank } /\left(\mathrm{W} /\left(\mathrm{m}^{2} .{ }^{\circ} \mathrm{C}\right)\right)\end{array}$ & 11.24 & 2.32 \\
\hline $\begin{array}{c}\text { Reduce the heat to fold into } 0.25 \mathrm{MPa} \text { saturated } \\
\text { steam } /(\mathrm{Kt} / \mathrm{a})\end{array}$ & 3.48 & 0.99 \\
\hline Payback time of Insulation investment cost/a & \multicolumn{2}{|c|}{0.15 .1} \\
\hline
\end{tabular}

2) Light oil storage tanks and pressure vessels: Light oil is easier to evaporate; liquefied petroleum gas saturated vapor pressure is significantly increased with increasing temperature. In the hot summer, the surface temperature of the liquefied petroleum gas tank can be up to $60^{\circ} \mathrm{C}$. For security purposes, factories tend to cool the oil and pressure vessel sink with water spray. the application of nanoceramic insulation coatings can achieved good insulation effect. Nano-ceramic insulation coating can form a insulation layer with certain strength and elasticity after drying, combining the characteristics of both paint and insulation materials. the nano-vacuum coating ceramic particles can reduce the thermal conductivity, increase reflectivity with less demanding on the surface to be coated rust; the strong integrity can reduce the "thermal bridge" effect; extending rate is more than $30 \%$, providing good ductility; moisture resistance is good with a high acid and alkali resistance. Besides, it can be bonded well with the object surface. The image below is light oil tank: The left one without nano-ceramic coating has been severe corrosion; the right one has good insulation and corrosion resistance using nano-ceramic coatings.

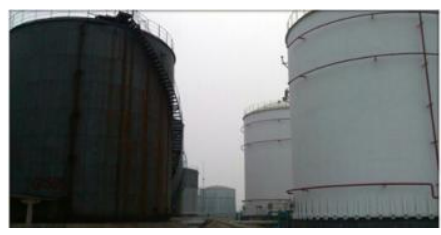

Figure 1. light oil tank

TABLE 2 ThE TEST DATA OF DIFFERENT COATING LIQUEFIED PETROLEUM GAS SPHERICAL TANK

\begin{tabular}{|c|c|c|}
\hline item & $\begin{array}{c}\text { Nano-ceramic } \\
\text { insulation coating }\end{array}$ & $\begin{array}{c}\text { Silver powder } \\
\text { paint }\end{array}$ \\
\hline volume $/ \mathrm{m}^{3}$ & 2000 & 1000 \\
\hline Liquid level $/ \mathrm{m}$ & 1.154 & 1.117 \\
\hline The environment temperature $/{ }^{\circ} \mathrm{C}$ & 32 & 38.8 \\
\hline The wind speed $/ \mathrm{m} \cdot \mathrm{s}^{-1}$ & 1.5 & 1.5 \\
\hline $\begin{array}{c}\text { surface temperature } \text { toward the } \\
\text { sun } /{ }^{\circ} \mathrm{C}\end{array}$ & 34 & 62 \\
\hline Sunshine overtemperature $/{ }^{\circ} \mathrm{C}$ & 2 & 23.2 \\
\hline
\end{tabular}

\section{The Field of Architecture}

Ceramic coating has been applied gradually the field of architecture , such as the large factory building, office, warehouse's roof, and the metope mobile communications equipment room, large garage roof, opera house, cinema, conference, exhibition centers' roof and so on .These kinds of building are large public places. It is also applied in the roof of large supermarket, the roof of top grade office building and the roof of large enterprise staff quarters.

The composite nano coating which has the function of reflection and heat insulation has been applied in the structure of residence of Jing su, Si chuan, Chong qing and so on. The composite nano coating which has the function of reflection and heat insulation is smeared on the surface of exterior wall of the datum architecture, and the incoming heat can be reduced by $48.0 \%$. This can make the building achieve the standards of energy saving. (2) The composite nano coating which has the function of reflection and heat insulation is smeared on the surface of energy saving building, this can reduce $48 \%$ of the incoming heat once again. What's more, due to the composite nano coating which has the function of reflection and heat insulation at the atmosphere of the infrared window $(7.5 \sim 14.0 \mu \mathrm{m})$ band has higher average hemisphere emissivity, its coating can emit heat into outer space all day long, the quantity can reach to $126 \mathrm{w} /(\mathrm{m} 2 . \mathrm{h})$. This function of radiation cooling can make the wall of the building and indoor storage heat released into the outer space quickly. The wall and indoor temperature can also be reduced at the same time. The 
energy saving effect of the function radiation cooling is very considerable. According to the calculation, The building of Chong qing of reflection and heat insulation can reduce 12 tco 2 of the emissions[1].

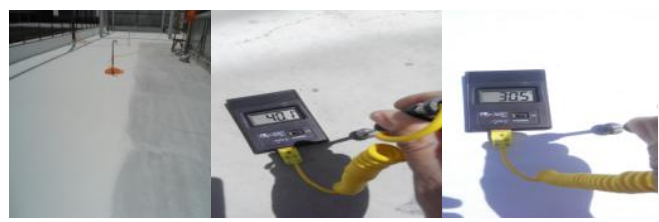

Figure 2. Tianjin general roof and a building roof surface temperature of nanostructure ceramic coatings is used to contrast (summer)

\section{The Research Progress AND Existing Problems}

The present ceramic coating study mainly focused on the three types: the mechanism of material thermal characteristics research, preparation research and the other characteristics research .

\section{A. The Material Thermal Characteristics Research}

In the material thermal characteristics research, the mechanism of heat transfer, heat transfer properties and the calculation model of the material and explores the calculation model are explored. This is the key point of research. It includes the analysis of heat transfer mechanism of the hollow microspheres filled polymer composites material by Jizhao Ling, Fenghua Li and so on. It points out that heat transfer is carrying out by three types which include solids and gas thermal conductivity, hollow microspheres thermal and natural convection of the gas inside the hollow microspheres. Based on the minimum thermal resistance principle and and equivalent thermal conductivity coefficient equality principle, it has established a theoretical model of heat transfer, and deduced the calculation formula of equivalent coefficient of thermal conductivity.[2] Ye Hong et al used SEM to analyze a kind of ceramic microspheres filled thermal insulation coatings. They have established the model which can calculate effective thermal conductivity by applying the method of numerical unit cell on the basis of this. [3]

Jiang Xiaojun et al draw lessons from the thoughts of Luo bo model that uniform distribution, the rules of the same size and shape and regular arrangement of air core ball take the place of stoma, and then adjust Luo bo formula for calculating the apparent coefficient of thermal conductivity of the coating. It can get a conclusion that empty core ball can obviously improve the insulation performance of the coating through test and mathematical derivation. Simultaneously, they discusses how the structure characteristics of hollow core ball and volume fraction impact on thermal conductivity of thermal insulation coating by the basic theory of heat transfer and put forward the mathematical expression of apparent coefficient of thermal conductivity of thermal insulation coating to guide the formulation of heat insulation coating and the optimization empty core ball structure.[4]

Define abbreviations and acronyms the first time they are used in the text, even after they have been defined in the abstract. Abbreviations such as IEEE, SI, MKS, CGS, sc, dc, and rms do not have to be defined. Do not use abbreviations in the title or heads unless they are unavoidable.

\section{B. Research of Material's Preparation}

Preparation of ceramic coating began in the last century, the United States developed the first space insulation ceramic layer which is composed of some suspended tiny particles in an inert liquid emulsion, and it is developed according to the space shuttle's heat conduction which is controlled by the Aerospace of the United States and the Administration of Space Universe. It is suitable for high pressure spraying, clean, with good function of resistance to heat radiation, thin layer insulation to heat, moisture-proof, anti-corrosion. Currently, the material of space insulation ceramic layer has been turned to general industrial and civilian heat and thermal insulation. In recent years, China also continues to develop ceramic coatings and make further development of nano-ceramic coatings, and making them widely used in petrochemical and architecture fields. These include:

China Academy of Building Research developed ceramic insulation coatings and make the decorative coating with thermal insulation function after the evaluation of scientific and technological achievements through the Ministry of Construction. The material is water-based liquid coatings, which is made by ultrafine hollow ceramic beads through pretreatment and high quality emulsion. Its main features are: hollow beads are formed in the layer of coatings, making the coating has a very high thermal reflectivity and emissivity, thus forming a good insulation effect, and effectively reduce summer cooling and winter heating energy consumption of buildings. [5]

ZhengQijun and others drew from the technology route of high-tech insulation porcelain coating used in foreign aerospace industry, and combined with the conditions of China then developed a thin layer of insulation coating with high emissivity coating successfully, which can compensate the lack of conventional insulation materials. The insulation coating is existed in the liquid coatings way, and its thermal resistance is larger when dried, especially it has high hot reflectivity, which can effectively reduce the radiation heat transfer. It is also easy for construction, thin coating, seamless, good adhesion, and setting waterproof, insulation and outer protection in one. Its insulation rating is $\mathrm{R} 21.1$, 0.79 degree heat reflective, thermal emissivity 0.83 , solid content of $54 \%$, which are close to similar foreign products' level, but the cost of it is only about $1 / 4$ of the foreign products. It can be directly used as a coating, and it can also be composed with other porous insulation materials to make a low radiation heat transfer structure, which can be refined as the coating layer of the oil tanks and storage tanks' insulation, pipes and equipments' cold insulation, and roofs' insulation that used in petroleum and petrochemical industries, that would has higher comprehensive energysaving efficiency. [6]

Liu Jie adopts that hollow ceramic microspheres mixed used with titanium dioxide can make good heat insulation effect. The coatings, that made by using barium sulfate to 
take place part of the high refractive index titanium dioxide, have excellent thermal insulation and low cost. [7]

Zhang Zhiqiang adopts hollow beads and infrared ceramic powder as functional filler, making the coatings with insulation; reflection, good radiation and other features, and he also test the functional filler of coating's influence to the thermal insulation. [8]

Peng Hong et add the nanometer grade room temperature far infrared ceramic powder in thermal insulation coatings, adopt single doped and mixed doped test method, optimize the dosage of the radiation functional filler, then acquire the best formula of radiation type external wall thermal insulation coating. [9]

Xian Caijun et. Adopted to nano composite reflective insulation coating which used hollow ceramic beads as filler has good thermal insulation effect, and it also has the indicators of the high quality coatings, through the National Building Materials Quality Testing Center's detection.[1]

The reflection coefficient of ceramic coatings depend on the comprehensive refraction coefficient of the coatings and the optical properties of the fillers, He Rui's study shows that titanium dioxide pigments is the best pigments and fillers with refraction. [10]

\section{Research of Material's Other Characteristics}

Because the ceramic materials are widely used in outdoor projects nowadays, the research on the corresponding of its physical and chemical properties becomes the premise of engineering application. Wang Xueying made a system research on ceramic coating corrosion performance of the seawater, including the study on the comprehensive performance of the seawater resistance, such as salt fog resistance, saturated Sodium Chloride Solution resistance, bittern resistance and so on, aiming at the demand of heavy anti-corrosion coatings, making epoxy resin as base material, according to the research of the effect of different size of ceramic on coating performance and filling gradation research, finally found out the best ceramic particle size and gradation of the best ceramic. [11]

Cai Sen highlighted and made the characterization on the corrosion resistance and wear resistance.[12] Zou Ming used the silicone modified acrylic resin as base material, adding nano silica and ceramic powder etc, making a coating with dual function of fireproof and corrosion resistance, and it also has good weather resistance and corrosion resistance.[13]

\section{Existing Problems}

1) Although there are current researches of the nano ceramic properties, such as corrosion resistance, abrasion resistance, it is not enough systematically and in-depth and needs further study on the engineering property.

2) Although the main material of nano ceramic is inorganic material, the additive has organic ingredients such as wood fiber. Hence, fireproof detection is necessary. Simultaneously, due to its various combinative forms with building, it will affect the overall fire prevention performance of components once it falls and damaged. So, we need to study the mainstream applied methods of fire prevention performance.

3) Because nano-ceramic has organic stuff, we should study the aging mechanism, toxicity performance under fire systematically.

4) At present the preparative cost is still high, it is difficult to make other component form besides coatings. So it needs to further research and majorization .

\section{CONCLUSIONS}

At present, China has enormous pressure on energy saving. Compared to traditional insulation materials, ceramic insulation coating has an absolute advantage on security. In recent years, Three big fire, the CCTV building, Shanghai 11.15 Jiaozhou Road, Shenyang Dynasty, are considered related to the traditional exterior insulation materials. I believe that there will be more broad application prospects for ceramic coating, including nano-ceramic coating considering the advantages in terms of thermal insulation, etc. after further optimization studies.

\section{ACKNOWLEDGEMENT}

This paper is sponsored by National "Twelfth FiveYear" Plan for Science \& Technology Support project number: 2012BAJ07B05.

\section{REFERENCE}

[1] Xian Caijun, XingYing,LiQuande, Some new progress of nano composite coating industry application technology. New material industry. NO.1 2011

[2] Liang Ji-zhao, Li Feng-hua, Heat transfer model polymer / composite hollow microspheres of heat transfer,Journal of sourth China Unitversity of Technology, vol33,No10.2005

[3] YE Hong, XU Bin, WANG Jun, YE Nuan-qiang, ZHUANG Shuangyong, The effective thermal conductivity of the thermal insulation, Journal of University of Science and Technology of China. 2006, 36( 4) : 360-363.

[4] JiangXiaojun, HuangChanggeng, YeHong, Lian Changchun. Influence of Cenospheres on Thermal Conduction of Thermal Insulating Coatings, paint and coatings industry, Vol 36 No. 4

[5] XinZhijun,WuSheng.Ceramic insulation coatings. Brick and tile.2006

[6] ZhengQijun,WangWei,YanFangen.Development and application of a thin layer of thermal insulation coatings. Petroleum Engineering Construction. 2003, vol29

[7] LiuJie.Research on Waterborne Solar-Reflective Heat-Insulating Coatings, Beijing University of Chemical Technology,2005

[8] ZhangZhiqiang, HuLing, ZhanHong. Testing Method and Heat insulating Principle of the Thermal Insulation Coatings for External Wall, Journal of Chongqing Jianzhu University. Vol.30 No.2

[9] PengHong,YangQi,ChenMingfeng.Development of Radiant Thermal Insulation Exterior Coating. paint and coatings industry. Vol. 42 No.6 Jun. 2012

[10] HeRui.Status and development of solar heat reflective coatings. Shanghai Coatings.vol42,2004

[11] WangXueying.A study of high performance anti-corrosion coatings for petroleum and petrochemical industry.Tianjin university.2010

[12] CaiSen.Characterization of ceramic wear-resistant anti-corrosion coating corrosion resistance. Coating industry.2004.no.8

[13] ZouMing,JiaMengqiu.Study and preparation of coating structure anticorrosive steel. Coating industry. Vol.41.No.100.2011 